Policing and collective efficacy: The relative importance of police effectiveness, procedural justice, and the obligation to obey police

Corresponding author:

Elise Sargeant, School of Criminology and Criminal Justice, Griffith University.

The final, definitive version of this paper has been published in the Policing and Society: An International Journal of Research and Policy, 2015 by Taylor \& Francis Online. $\odot$ Elise Sargeant.

http://www.tandfonline.com/doi/pdf/10.1080/10439463.2015.1122008?needAccess=true 


\title{
Policing and collective efficacy: The relative importance of police effectiveness, procedural justice, and the obligation to obey police
}

\begin{abstract}
The role of police in building collective efficacy remains an unanswered question. This paper employs a sample of 4,403 people living in 148 neighbourhoods in Brisbane, Australia, to examine the relationship between perceptions of police and collective efficacy. Results indicate that even when controlling for neighbourhood compositional and structural characteristics, trust in police effectiveness and procedural justice are the key variables explaining collective efficacy. Although trust in police effectiveness and procedural justice does not predict neighbourhood differences in collective efficacy, they do explain variations in perceptions of collective efficacy among those residents in a given neighbourhood. These findings reveal that when people trust the police are effective and procedurally just, they are more likely to view their neighbourhoods as collectively efficacious. This research suggests that police can help to encourage collective efficacy, and potentially reduce crime, by communicating their effectiveness and delivering procedural justice to citizens.
\end{abstract}

Keywords: collective efficacy, police legitimacy, trust in procedural justice, trust in police effectiveness

\section{Introduction}

Neighbourhood regulation is not solely within the domain of the police. Police are not omnipresent, and they rely on citizens to be their "eyes and ears". Police need citizens to report crime, to supervise their neighbours' properties, to participate in neighbourhood associations, and to be involved in community-policing activities like citizen patrols. Indeed, the success of community policing is dependent on citizen support and involvement (Greene 2000; Skogan 2006).

Police recognise the valuable role citizens play in regulating crime. They encourage citizens to report crime (e.g. "crime stoppers" campaigns) and to engage in community crime prevention activities (e.g. Neighbourhood Watch). Police agencies also acknowledge the 
merit of positive police-citizen engagement and of maintaining public goodwill. When citizens are satisfied with police they are more likely to "play an active role in assisting officers in the performance of their police duties" (Frank et al. 2005, p. 212).

We know police behaviour can encourage citizens to help the police to address crime problems (Tyler and Fagan 2008), but what about more informal acts of community regulation? Over a decade ago, Kubrin and Weitzer (2003, p. 384) outlined how exploring the "formal-informal control nexus" was a necessary future direction for social disorganisation research. Yet Sampson (2013, p. 36, emphasis in original) recently argued that the role of police in "building collective efficacy" remains an unanswered question.

This paper investigates the relationship between policing and collective efficacy, disaggregating the relative effects of police effectiveness, procedural justice and the obligation to obey police. Determining how collective efficacy can be sustained and encouraged matters as it can aid police in their endeavours to support informal community regulation and inform police practice in communities lacking collective efficacy (Renauer 2007). This research draws on data collected in the Australian Community Capacity Study (ACCS), a large-scale neighbourhood survey of 4,403 residents in 148 neighbourhoods in Brisbane, Australia. Before methods and results are presented, research explicating the formal-informal control relationship is reviewed.

\section{Perceptions of Police and Collective Efficacy}

Even as the link between formal and informal social control is acknowledged in neighbourhood research (see for example Bursik and Grasmick 1999; Hunter 1985), only a handful of empirical studies have examined the relationship between perceptions of police and community collective efficacy. The few which do, tend to consider broad-brush measures of "satisfaction with" or "faith in" the police, and cumulatively produce conflicting results. For example, Silver and Miller (2004) and Warner and Burchfield (2011, p. 622) find 
evidence that "satisfaction" and "faith in police" predict informal social control (one component of collective efficacy); whereas other studies suggest this may not be the case (e.g. Sun et al. 2004; Warner 2007).

Beliefs about the police, or perceptions of police, can be conceptualised in a number of ways. Trust and legitimacy perspectives find a great deal of support in the literature and currently dominate the landscape of policing research. Police legitimacy is a powerful construct because it helps us to understand the authority police hold, why police have the right to exercise this authority, why police can elicit obedience from the public and perhaps even to explain why citizens hold particular norms and values.

Empirical research about police legitimacy demonstrates how citizens' behavior toward police is influenced by police legitimacy. When people perceive the police are legitimate, they are more willing to cooperate and comply with police (e.g. Sunshine and Tyler 2003; Tyler and Fagan 2008). Trust in police also explains citizen reactions to police: when people perceive the police are trustworthy they are more likely to be satisfied with police and willing to cooperate with them (e.g. Tyler 2005).

Despite the proliferation of research about legitimacy and trust, these constructs remain somewhat abstract, and debate over the conceptualization and operationalization of trust and legitimacy is plentiful. Tom Tyler's original conceptualisation of legitimacy comprises two features: the perceived obligation to obey police and institutional trust (e.g. Sunshine and Tyler, 2003; Tyler and Huo, 2002). More recently, it is argued that trust is a distinct construct to obligation (e.g. Reisig et al., 2007), and numerous scholars offer up more comprehensive conceptualisations of legitimacy. One example is the work of Anthony Bottoms and Justice Tankebe. Drawing on the works of Beetham (1991) and Coicaud (2002), Bottoms and Tankebe (2012) argue police legitimacy comprises numerous, distinct, components including police effectiveness, distributive fairness, procedural fairness and 
lawfulness (i.e. the degree to which police follow the law) (see also Tankebe 2013). Another example is that of Jon Jackson and his colleagues. Jackson et al. (2013, p. 152) describe the way that legitimacy comprises obedience (as in Tyler's original conceptualisation) but also depends on moral alignment (i.e. shared values and morals between the police and the public) and legality (i.e. police "follow their own rules") (see also Beetham, 1991; Tankebe 2009). Different to legitimacy, trust is about our expectations of others (Hawdon 2008). In the context of police and policing there are two types of expectations we, as citizens, have of the police. First that police are procedurally just or fair, and second that police are effective, that do a good job to prevent and control crime, and respond to disorder (Jackson et al., 2013).

The current surge in empirical research around perceptions of police and police legitimacy, leads us to consider the role of the perceived legitimacy of the police, and trust in police, when exploring the impact of policing on citizen norms for behaviour. Disentangling trust from legitimacy leads us to consider how different aspects of police behaviour (or how people perceive police behaviour) might help us to better understand community norms including collective efficacy.

The relationship between perceptions of police and collective efficacy can be viewed as a function of community norms and values, and feelings of security. In their role as moral guardians, the police remind us of the behaviours that are criminal, deviant and unacceptable. Through their actions in upholding the law, the police thus contribute to the maintenance of norms and values in society and in local communities (Kochel 2009, 2012; LaFree 1998; Sun et al. 2004; Triplett et al. 2003). The role of police in upholding norms and values, may however be limited if their own legitimacy is called into question, or when people do not trust the police. When police lack legitimacy, "shared norms and values" in a community are eroded (Kochel 2012; LaFree 1998; Sun et al. 2004) such that community residents will "struggle to develop a working trust" and "cannot be confident that other neighbors will act 
in the best interest of the neighborhood, nor can they predict how neighbors might respond should they intervene" (Kochel 2012, p. 389). When citizens do not trust the police, citizens are also likely to perceive the absence of police protection. If the police are not viewed as effective, responsive, and fair, neighbourhood residents may "be reluctant to take the personal risks involved in acting informally to safeguard social order in the neighborhood" (Silver and Miller 2004, p. 559; see also Bottoms 2006; Innes 2004; 2004b; Innes and Fielding, 2002; Innes et al. 2004). ${ }^{1}$ When police are not perceived to be trustworthy and legitimate it is therefore unlikely that community residents will view their neighbourhood as collectively efficacious.

When linking beliefs about the police with collective efficacy Anthony Bottom's (2006) discussion of "control signals" is enlightening. A "control signal" is defined as "an act of social control that communicates an attempt to regulate disorderly and deviant behaviour" (Innes 2004, p. 556), where a positive control signal indicates control and a negative control signal indicates a lack of such control. When police are ineffective and illegitimate they communicate negative control signals, which are likely to lead to community withdrawal whereas "positive control signals should encourage, as an effect, residents' willingness to engage in the interventions that are a key element in collective efficacy" (Bottoms 2006, p. 269, emphasis in original). Stated differently, when police indicate effectiveness "this should persuade ordinary residents that social order in the area is begin seriously attended to by the relevant authorities, and this may, in turn, encourage residents to intervene more readily in problematic or escalating situations" (Bottoms 2006, p. 269). When citizens trust in police and believe police are legitimate community residents will therefore be assumed more likely to intervene in community problems.

These theoretical perspectives suggest beliefs about the legitimacy and trustworthiness of police should be central to our understanding of collective efficacy in 
neighbourhoods. Kochel (2012, p. 395) sought to test this association in Trinidad and Tobago, examining the effects of both police service quality and the obligation to obey police (one component of legitimacy) on collective efficacy. She found that while police service quality was positively associated with neighbourhood collective efficacy, the obligation to obey police did not produce a significant effect. Kochel (2012) concluded that collective efficacy may not be a function of police legitimacy. In contrast, a qualitative study in Australia found that policing agencies can best encourage collective efficacy when they "foster a sense of effectiveness, use inclusive and partnership-oriented strategies" and encourage perceptions of police legitimacy (Sargeant et al. 2013, p. 70). Similarly, Jackson et al. (2013), in their study of London neighbourhoods, found collective efficacy is linked to trust in procedural fairness, trust in police effectiveness, the obligation to obey police and moral alignment. Considering the mixed findings of prior studies, more research is needed in order to understand the relationship between perceptions of police and collective efficacy.

\section{The Current Paper}

It is well established in criminological research that informal social control mechanisms are central to crime control and prevention. In their seminal paper Sampson et al. (1997) found collective efficacy in Chicago (operationalised as a combined measure of social cohesion and trust in neighbours and informal social control) explained variations in crime across neighbourhoods, concluding that collective efficacy was the key to sustaining low rates of violence, even when residents were faced with structural disadvantage, ethnic heterogeneity and residential mobility. However even as collective efficacy is found to be desirable, the majority of collective efficacy studies have focused on the positive outcomes of collective efficacy rather than its antecedents (Browning and Cagney, 2002; Browning et al. 2005; Franzini et al. 2005; Maimon et al. 2010; Zhang et al. 2007). Policing is one assumed 
antecedent of collective efficacy that has not yet been fully explored or understood. Researchers expect that perceptions of police will help to explain collectively efficacious beliefs and behaviour in neighbourhoods (see Kubrin and Weitzer 2003; Silver and Miller 2004). However the nature of this relationship remains unclear.

This paper addresses the question: What exactly it is about police behaviour - or more importantly, how people perceive police behaviour - that encourages collective efficacy? This study builds upon the findings of prior research to examine the relationship between different elements of police legitimacy and collective efficacy in a Western democratic setting. Using data collected in the Australian Community Capacity Study (ACCS) survey in Brisbane, Australia I examine how beliefs about the police might help to explain collective efficacy.

\section{Data and Measurement}

\section{Sample Selection}

The Wave 3 ACCS survey is a study of 4,403 residents living in 148 randomly selected suburbs or neighbourhoods ${ }^{2}$ in and around the city of Brisbane, Australia. Communities included in the ACCS Wave 3 were selected based on their involvement in previous waves of the study (for further information see Mazerolle et al., 2012). In Wave 3, participants from Wave 2 who had agreed to be contacted to participate in future research, comprised the longitudinal sampling frame. In order to increase the sample size within neighbourhoods an additional "top-up" sampling frame was also produced using Random Digit Dialling (RDD). Households were eligible for selection if they were private dwellings with telephones in the 148 selected neighbourhoods in the Greater Brisbane Statistical Division (BSD). The sample of neighbourhoods has a mean population size of 5,268 with a standard deviation of 4,731. From within selected households, the participant who had most 
recently had a birthday, and was aged over 18, was invited to participate. Interviews were conducted by the Institute for Social Science Research (ISSR) at the University of Queensland between the $25^{\text {th }}$ of August 2010 and the $15^{\text {th }}$ of December 2011. Interviews were administered by trained interviewers using Computer Assisted Telephone Interviewing (CATI). The response rate was 41.8 percent. In addition to this primary sample, an ethnic booster sample was recruited to ensure the ACCS was representative of notable ethnic groups in Brisbane. Nine hundred people from Indian, Vietnamese and Arabic-speaking backgrounds were surveyed in and around the 148 communities in the primary sample using the "common surname" method (Murphy et al. 2012, p. 5). This method involved collating lists of common surnames which included 116 for the Indian group, 34 for the Vietnamese group and 99 for the Arabic speaking group. Sampling was conducted by an agency specialising in the sampling of culturally and linguistically diverse (CALD) populations. The common surname method has been used successfully in other large-scale surveys to capture CALD populations (see Challice and Johnson, 2005). The response rate for the ethnic booster sample was 21.8 percent (Murphy et al. 2012). ${ }^{3}$

Participants in the ethnic booster sample were surveyed face-to-face in their chosen language using the same survey instrument as the primary sample (with some additional survey questions). Participants who were in-scope (i.e. who resided in the 148 neighbourhoods) were combined to form the final sample for analysis. The resultant sample size was 4,403 people.

\section{Measures}

\section{Collective efficacy}

The dependent variable in this study is collective efficacy. The measure of collective efficacy employed in the ACCS survey was adapted from the Project on Human Development in 
Chicago Neighbourhoods and encapsulates the linkage between informal social control and social cohesion and trust (e.g. Sampson et al. 1997). Participants were asked to indicate the likelihood of their neighbours intervening in five informal social control scenarios, and their level of agreement with four items measuring social cohesion and trust. Items were measured on a five-point Likert scale ranging from $1=$ "very unlikely" to $5=$ "very likely" for informal social control, and $1=$ "strongly disagree" to $5=$ "strongly agree" for social cohesion and trust (Cronbach's Alpha $=.750)$. Items included in the collective efficacy scale and in the other scales are detailed below in Table 1.

\section{[Insert Table 1]}

\section{Beliefs about the Police}

Three measures were employed to capture police legitimacy and trust in police: the obligation to obey police, trust in procedural justice and trust in police effectiveness. Traditionally the obligation to obey police and institutional trust have been used to measure legitimacy (Kochel 2012; Reisig et al. 2007; Sunshine and Tyler 2003; Tankebe 2013; Tyler 2006; Tyler and Fagan 2008). Although scholars have recently distinguished obligation to obey police from trust when measuring legitimacy (e.g. Jackson et al. 2013; Kochel 2012; Reisig et al. 2007). Scholars have also conceptualised trust in police as comprising two components: trust in procedural fairness and trust in police effectiveness (Jackson et al., 2012).

To measure the obligation to obey police, participants indicated their level of agreement with two items. Items were measured on a Likert scale of $1=$ "strongly disagree" to $5=$ "strongly agree" (Cronbach's Alpha $=.701)$. To measure trust in procedural justice, participants were asked to indicate their level of agreement with six statements capturing two elements of procedural justice: the "quality of treatment" and the "quality of decision making” by police (Reisig et al. 2007, p. 1007; Mazerolle et al., 2012). Responses were 
measured on a Likert scale ranging from $1=$ "strongly disagree" to $5=$ "strongly agree" (Mazerolle et al., 2012) (Chronbach's Alpha $=.891)$. To measure trust in police effectiveness the ACCS drew on the work of Tyler and others (e.g. Hinds and Murphy 2007; Murphy et al. 2008; Sunshine and Tyler 2003; Tyler and Huo 2002; Tyler and Wakslak 2004). Respondents were asked to indicate how good a job police in the community/neighbourhood do at four elements of their job. Response categories were 1 "very poor", 2 "poor", 3 "average", 4 “good”, and 5 "very good" (Mazerolle et al., 2012) (Cronbach’s Alpha $=.883) .{ }^{4}$

\section{Control variables}

Prior studies have found demographic variables to be associated with both perceptions of police (Brown and Benedict 2002), and collective efficacy (Kochel 2012). Demographic control variables were therefore also included in the analyses. Dichotomous variables were included to capture a participant's gender (1 “female"; 0 "male”), language (1 "speaks English at home", 0 “other"), home ownership (1 “owns home"; 0 "other"), length of time at current address ( 1 "lived at address less than 5 years"; 0 "lived at address 5 years or more"), employment status (1 “unemployed seeking work", 0 “other"), violent victimisation (1 "has been a victim of violence in the past 12 months", 0 "other"), and contact with police (1 "has had contact with police in the last 12 months", 0 "no contact"). Participants were also asked to report on the number of dependent children under the age of 18 living in the household. This variable was skewed toward zero, so the log of the number of dependent children (plus a constant) was taken.

Neighbourhood-level measures of disadvantage, residential mobility, ethnic heterogeneity and the prior rate of violent crime were obtained from the Australian Bureau of Statistics (ABS) (from the most recent census in 2006) and the Queensland Police Service (QPS) (see Mazerolle et al., 2012). Neighbourhood structural characteristics are well known 
for explaining collective efficacy (e.g. Sampson et al. 1997), and attitudes toward police (e.g. Reisig and Parks 2000; Rhineberger-Dunn and Carlson 2009). Controlling for prior violent crime rates and neighbourhood structural characteristics reduce the likelihood of observing spurious relationships between policing and collective efficacy (Silver and Miller 2004).

Disadvantage was approximated using the proportion of unemployed residents in the neighbourhood. Residential mobility was measured as the proportion of people in the neighbourhood with a different usual address five years ago. Ethnic heterogeneity was measured as the proportion of people in the neighbourhood who spoke a language other than English (LOTE); neighbourhoods with a higher proportion of people who spoke a language other than English were assumed to be ethnically heterogeneous. As the LOTE variable was skewed, the log was computed. To control for the prior rate of violent crime ${ }^{5}$, violent crime rates for the years 2007, 2008, and 2009 were calculated and added together to form a single measure. Violent crime captures homicide (murder), other homicide (e.g. attempted murder), assaults (excluding sexual assault), and robbery (Mazerolle et al., 2012). The rate of prior violent crime in the neighbourhood was calculated per 100,000 people in the neighbourhood. As this variable was positively skewed toward zero, the log of the violent crime rate (plus a constant) was taken.

\section{Analysis}

\section{Factor analysis}

To access the factor structure and confirm the discriminant validity of the measures of perceptions of police, as well as to access the factor structure of collective efficacy, confirmatory factor analysis was undertaken using STATA 13. As we might expect with a large sample size, the four-factor model (obligation to obey, procedural justice, police effectiveness, collective efficacy) was not a perfect fit for the data $\left(\chi^{2} 1099.17(181) ; p=.000\right)$ 
(Bollen 1989). However model fit indices suggest the four-factor solution provides a good fit for the observed data (RMSEA .037; CFI .970; TLI .965; SRMR .025). ${ }^{6}$ Factor scores were saved and used in the analyses.

\section{Multilevel models}

Considering the nature of the sample (individuals nested within suburbs or neighbourhoods), multilevel models were computed in STATA 13 to examine the relationship between the independent variables and the dependent variable collective efficacy. Multilevel modelling has been consistently used in prior research on collective efficacy, as it allows the researcher to consider the responses of individuals within their neighbourhood context (Raudenbush and Bryk 2002). Prior to the computation of the multilevel models, descriptive statistics were computed and examined (see Table 2), and variables were transformed where necessary (see Measures section above). Variance Inflation Factors (VIF) were computed to test for multicollinearity. The only variables exceeding a VIF of 3 were the age and age-squared variables, which were included as a quadratic term. Residual diagnostics were examined for normality and the removal of multivariate outliers produced no substantive change in the final models, therefore all valid cases were included in the analyses. Three multilevel models were computed using the mixed command in STATA 13. Model 1 is a compositional model and includes the demographic characteristics and other individual-level control variables, Model 2 includes the neighbourhood structural characteristics and Model 3 includes the policing variables. Intraclass Correlation Coefficients (ICCs) were calculated for each model in order to observe the proportion of neighbourhood-level variance in collective efficacy explained by the addition of variables to the model (see Table 3). Table 4 below presents the results of the models.

[Insert Table 2] 
[Insert Table 3]

[Insert Table 4]

\section{Results}

Compositional variables were entered in Model 1. The addition of these compositional variables reduced the ICC of collective efficacy from 16.64 percent (null or empty model) to 15.19 percent, accounting for 8.71 percent of the between-neighbourhood variation in collective efficacy (see Table 3). All compositional variables were significantly associated with collective efficacy with the exception of speaking English at home, unemployment, and contact with the police. Age was entered as a quadratic term (i.e. age and age-squared). The quadratic term for age indicated that age was positively associated with collective efficacy until the age of 75 (see Table 4). After this turning-point age was negatively and significantly associated with collective efficacy: those aged $>75$ held less positive perceptions of collective efficacy as age increased. As we would expect, short-term residents (living at their current address for 5 years or less $)$ held less positive perceptions of collective efficacy $(z=-2.86 ; p=$ $.004)$, compared to longer-term residents. Being female $(z=6.32 ; p=.000)$, owning your own home $(z=3.66 ; p=.000)$ and having more dependent children $(z=4.20 ; p=.000)$ were all positively associated with collective efficacy. These variables speak to a level of embeddedness in the local neighbourhood, and neighbourhood desirability, which naturally correlate with collective efficacy. As we would expect, people who had been a victim (or a member of their household had been a victim) of violent crime in the past 12 months held less positive perceptions of collective efficacy $(z=-4.70 ; p=.000)$.

Structural characteristics were entered in Model 2. The addition of the structural variables reduced the ICC from 15.19 percent to 4.48 percent, accounting for the majority of the between-neighbourhood variation in collective efficacy (73.08 percent) (see Table 3). 
Consistent with prior research, when first entered into the model, all of the neighbourhood structural variables were significantly associated with collective efficacy, with the exception of living at a different address 5 years ago $(z=1.48 ; p=.138)$ (see Table 4$)$. The prior rate of violent crime was negatively associated with collective efficacy $(z=-4.65 ; p=.000)$, as was a high unemployment rate $(z=-8.03 ; p=.000)$, and a high proportion of people who speak a language other than English in the neighbourhood $(z=-4.37 ; p=.000)$. That is, people living in neighbourhoods with higher rates of prior violent crime, higher rates of unemployment, and a greater proportion of people who speak a language other than English, were less likely to perceive higher levels of collective efficacy in their neighbourhood. These results are consistent with prior research that has found violent crime rates, disadvantage, residential mobility, and ethnic heterogeneity predict lower levels of collective efficacy. These findings support the social disorganisation model of collective efficacy in neighbourhoods.

Obligation to obey police and trust in police variables were entered in Model 3. The addition of these variables did not account for any of the between-neighbourhood variation in collective efficacy. Post-hoc investigation suggests this may be due to low variation in perceptions of police across neighbourhoods. ${ }^{7}$ Despite low variation across neighbourhoods, trust in police effectiveness $(z=16.87 ; p=.000)$ and trust in procedural justice $(z=7.19 ; p=$ .000) were the strongest predictors of collective efficacy included in the final model and were positively and significantly associated with collective efficacy (see Table 4). The obligation to obey police on the other hand was not significantly associated with collective efficacy $(z=$ $1.48 ; p=.140)$. These results indicate that even as perceptions of police do not vary greatly across neighbourhoods, individuals perceptions of trust in police effectiveness and trust in procedural justice in their neighbourhood are strongly associated with beliefs about neighbourhood collective efficacy. The obligation to obey police, on the other hand, appears to hold no explanatory power. 


\section{Discussion}

Prior research into the mechanisms underpinning collective efficacy has begun to consider the role that police may play in encouraging collective efficacy in communities. This study advances on our current empirical understanding by exploring the role that various elements of beliefs about police may have in explaining neighbourhood collective efficacy. While cross-sectional data cannot uncover the causal order of the relationship between perceptions of police and collective efficacy, this study advances prior research by quantitatively comparing the obligation to obey police and trust in police effectiveness and procedural justice, and their relationship to collective efficacy, in a Western developed context.

When controlling for neighbourhood compositional and structural characteristics, I find trust in police effectiveness was the strongest predictor of collective efficacy, followed by trust in procedural justice. These findings indicate people's trust in police does help to inform their beliefs about collective efficacy in their neighbourhood. On the other hand, the obligation to obey police does not help to explain collective efficacy. These results are consistent with those of Kochel (2012), who finds that while police service quality (similar to police effectiveness) predicts collective efficacy, the obligation to obey police does not. In Kochel's (2012) study, the null findings may have been attributed to the way obligation to obey police was measured. Kochel (2012) acknowledges that the single-item measure of obligation to obey used in her study, may have been inadequate (i.e. a single item measure is generally viewed to be less reliable than a multi-item scale). Null findings in the current study may be similarly attributed to measurement issues (i.e. obligation to obey was measured using only two items).

Distinguishing trust in police and the obligation to obey police may also help to explain these null findings. As Hawdon (2008) argues, the distinction between "trust" and "legitimacy" can be understood as the distinction between neighbourhood police officers and 
the policing institution. Hawdon (2008, p. 186) suggests: "legitimacy applies to a role position within the impersonal social order" whereas "trust applies to whether or not the behaviour of an individual conforms to the social expectations concerning the role he or she occupies". In the research site described in the current study, policing is centralised, with all neighbourhoods in the sample coming under the jurisdiction of one state police organisation the Queensland Police Service (QPS). While this state policing service is managed regionally, there is a central hierarchy and shared goals and values. Following Hawdon's (2008) definition of legitimacy, the obligation to obey police, in this context, is more strongly linked to the policing institution at the state-level than to police officers who work in the neighbourhood. In contrast, trust in police effectiveness and procedural justice may be more to do with local neighbourhood police officers. For example, one may believe that the institution of the police (e.g. the QPS) holds legitimate authority, and might therefore be willing to obey the police in general, while at the same time distrusting an individual police officer in one's neighbourhood, or vice versa (Hawdon 2008). This may also help to explain why trust in procedural justice and police effectiveness are positively and significantly associated with collective efficacy in the current study, whereas the obligation to obey police is not. That is, trust in procedural justice and police effectiveness are measures more specific to the neighbourhood context, while the obligation to obey the police may be generalised to the state police service as a whole.

Translating these findings for police practice, this study suggests police may be able to encourage collective efficacy and subsequently reduce crime in communities by improving trust in police effectiveness and procedural justice. While "being effective" may be somewhat self-explanatory to police, communicating effective outcomes to citizens can be actively improved upon. For example, Hohl et al. (2010, p. 500) examined the effect of distributing a newsletter designed to enhance perceptions of police-community "engagement", "fairness" 
and police "effectiveness". Using quasi-experimental methods, Hohl et al. (2010) found that delivering a newsletter to households could improve overall confidence in the police (Hohl et al. 2010). Strategies like this can be utilised to target communities with low collective efficacy, and subsequently improve trust in police effectiveness where collective efficacy is lacking.

Recent research also indicates that police can actively work to improve citizens' trust in procedural justice. Mazerolle et al. (2011) found that when police demonstrated procedural justice at Random Breath Test (RBT) encounters with citizens, citizens reported higher trust and confidence in police. Such strategies can be designed to bring police into contact with neighbourhood residents who might normally have few interactions with police and give police the opportunity to demonstrate procedural justice.

\section{Limitations}

The current study is not without limitations. First, the analysis is cross-sectional. Using data collected at a single point in time, I examined how beliefs about police may contribute to collective efficacy. As Kochel (2012) notes, collective efficacy is a clear crime prevention strategy, and police should therefore be interested in promoting and sustaining collective efficacy in communities. As community representatives and upholders of the law, legitimate police send powerful "control signals" to the communities they represent, which are expected to encourage community residents to intervene in community problems (Bottoms, 2006, p. 269). Yet just as community residents draw on their understandings of the police to gain insight into their community surrounds, they may also draw on their community surrounds in order to make judgements about the police. Jackson and his colleagues (2012) conceptualise the relationship between collective efficacy and legitimacy in this way. They suggest that community residents will draw on their understanding of their neighbourhood, including perceived collective efficacy, when making judgements about the police. The idea here is that 
police are representatives of the communities they serve, therefore the police will be judged on the cohesiveness of these communities. In order to resolve the causal direction of the relationship between policing and collective efficacy, future research should explore this question using longitudinal data.

The measurement of police legitimacy is the second limitation of the current study. As described earlier, the way police legitimacy is defined and measured is a contentious issue in prior policing research. In consequence, police legitimacy has been defined and measured in a variety of different ways (for notable contributions see Bottom's and Tankebe, 2012; Jackson et al., 2012). Future research should therefore examine other measures of legitimacy not measured in this study, particular those pertaining to the elements of moral alignment and legality. These elements encapsulate beliefs that the police share common values with the public they serve and abide by the rules they enforce - factors that seem particularly relevant to collective efficacy. As Kochel explains: "General agreement among members of a group about legitimacy reinforces normative behavior, increases the predictability of everyday behavior (because people comply), and enhances interpersonal trust that others will conform to the shared expectations for behaviour...When significant proportions of residents doubt the legitimacy of institutions such as the police, the conventional values that police represent will become less respected, eroding a foundation on which neighborhoods can build consensus about the appropriate behaviors to expect in the neighborhood". Accordingly, if police do not share common values with community residents, and do not act according to the law, it will be difficult for community residents to develop collective efficacy.

\section{Conclusion}

This study disentangles the aspects of modern policing that are related to collective efficacy in neighbourhoods. Overall, findings suggest that even though the obligation to obey police is 
not linked to collective efficacy, both trust in police effectiveness and procedural justice support collectively efficacious beliefs. These findings point to the necessity of future research to continue to explore the role that different aspects of policing can play in supporting collective efficacy as well as other community processes like community norms (see Antrobus et al. 2015) and social identity (Bradford 2014). As the current study suggests, if trust in police effectiveness and procedural justice matter for collective efficacy, as well as for other pro-social outcomes such as cooperation and compliance with police, improving public perceptions becomes more important than ever (Frank et al. 2005). Police are cognisant that citizens play an indispensable role in regulating neighbourhoods and providing assistance to police. The findings of the current paper suggest that police can make use of this valuable resource, and actively encourage citizens to engage in community regulation. As the current study shows, improving trust in police effectiveness and procedural justice can have flow-on effects such as improving collective efficacy and perhaps, ultimately, reducing crime (Sampson 2013; Sampson et al. 1997).

\section{Acknowledgements}

[De-identified]

\section{Notes}

1. I also note that a lack of police legitimacy and trust may be linked to vigilantism, when police are illegitimate and ineffective, community residents may revolt and solve problems through the use of violence (Black 1983; Haas et al. 2014; Tankebe 2009). However, as collective efficacy is associated with pro-social action, it is more likely that the relationship between police legitimacy, trust and collective efficacy will be positive (Silver and Miller, 2004).

2. In Australia, the term "suburb" is similar to the use of the term "neighbourhood" or "local community" used to describe a geographically bounded unit of analysis (Chaskin 2001). The suburb also fits with Brisbane residents' notions of their local community. For example, in a pilot study, ACCS researchers found that respondents associated the term "community" with their residential suburb (Mazerolle et al. 2010). In addition, the suburb is the smallest unit of 
analysis for which the ACCS could obtain administrative data at the time of data collection (Mazerolle et al., 2012). As such, the suburb is considered the best geographic boundary for the purposes of this study.

3. The discrepancy between the response rates between the main sample and the ethnic booster sample is likely attributable to the sampling design. In the main sample a proportion of participants were longitudinal participants who had completed a similar survey some years earlier. These participants were subsequently more likely to agree to participate in a follow-up survey than the booster sample participants who received 'cold calls'. Overall, lower response rates reflect the recent trend for telephone surveys (for example, Pickett et al., 2012).

4. Cluster means were also calculated for each of the key variables of interest (police effectiveness, procedural justice and the obligation to obey police), to test for contextual effects. Individual-level measures of these policing constructs were then cluster-mean centered to allow different within and between effects and to avoid issues of multicollinearity (Rabe-Hesketh and Skrondal 2012; Raudenbush 1989). Upon entry into the statistical models tests were computed to determine whether or not the resultant coefficients for individual and cluster-mean measures of each construct were the same. Test statistics indicated that for each of trust in police effectiveness, trust in procedural justice and the obligation to obey police, there was no difference between the within- and between- effects. As such only individuallevel policing variables were entered in the final models.

5. Rates of violent crime are a good indicator of crime in a neighbourhood, as violent crime is more often reported than other types of crime (Mazerolle et al. 2012).

6. To improve model fit, error terms were covaried for "If a group of community children were skipping school and hanging around on a street corner, how likely is it that people in your community would do something about it?" and "If some children were spray painting graffiti on a local building, how likely is it that people in your community would do something about it?" as well as for "People in this community are willing to help their neighbours" and "This is a close-knit community". Theoretically, we might expect these error terms to be correlated in that skipping school and graffiti may go hand in hand in communities, as would being willing to help one's neighbours and living in a close-knit community.

7. Empty multi-level models predicting trust in police effectiveness, trust in procedural justice and the obligation to obey police were computed, demonstrating this low variation. ICCs were 3.5 percent, 2 percent and 1 percent for trust in police effectiveness, trust in procedural justice and the obligation to obey police respectively. 


\section{References}

Antrobus, E., et al., 2015. Community norms, procedural justice, and the public's perceptions of police legitimacy. Journal of contemporary criminal justice, 31, 151-170.

Beetham, D., 1991. The legitimation of power. London, U.K.: Macmillan.

Black, D., 1983. Crime as social control. American sociological review, 48(1), 34-45.

Bollen, K. A., 1989. Structural equations with latent variables. New York: John Wiley and Sons.

Bottoms, A., 2006. Incivilities, offence and social order in residential communities. In: A. Von Hirsch and A. P. Simester eds. Incivilities: Regulating offensive behaviour. Oxford, UK: Hart Publishing.

Bottoms, A., and Tankebe, J., 2012. Beyond procedural justice: A dialogic approach to legitimacy in criminal justice. Journal of criminal law and criminology, 102(1), 120 170.

Brown, B., and Benedict, W. R., 2002. Perceptions of the police: Past findings, methodological issues, conceptual issues and policy implications. Policing: An international journal of police strategies and management, 25(3), 543-580.

Browning, C. R., and Cagney, K. A., 2002. Neighborhood structural disadvantage, collective efficacy, and self-rated physical health in an urban setting. Journal of health and social behavior, 43(4), 383-399.

Browning, C. R., Leventhal, T., and Brooks-Gunn, J., 2005. Sexual initiation during early adolescence: The nexus of parental and community control. American Sociological Review, 70(5), 758-778.

Bursik Jr, R. J., and Grasmick, H. G., 1999. Neighborhoods and crime. Lexington Books.

Challice G. and Johnson, H., 2005. The Australian component of the 2004 International Crime Victimisation Survey. Technical and Background Paper (Vol. 16). Canberra: Australian Institute of Criminology. 
Chaskin, R. J., 2001. Building community capacity: A definitional framework and case studies from a comprehensive community initiative. Urban affairs review, 36, 291-323.

Coicaud, J., 2002. Legitimacy and politics: A contribution to the study of political right and political responsibility. Cambridge, U.K.: Cambridge University Press.

Frank, J., Smith, B. W., and Novak, K. J., 2005. Exploring the basis of citizens' attitudes toward the police. Police quarterly, 8(2), 206-228.

Franzini, L., Caughy, M., Spears, W., and Esquer, M. E. F., 2005. Neighborhood economic conditions, social processes, and selfrated health in low-income neighborhoods in Texas: A multilevel latent variables model. Social science and medicine, 61, 11351150.

Greene, J. R., 2000. Community policing in America: Changing the nature, structure, and function of the police. Criminal justice 2000: Policies, processes, and decisions of the criminal justice system, 3, 299-370.

Haas, N. E., de Keijser, J. W., and Bruinsma, G. J., 2014. Public support for vigilantism, confidence in police and police responsiveness. Policing and society, 24(2), 224-241.

Hawdon, J. E., 2008. Legitimacy, trust, social capital, and policing styles: A theoretical statement. Police quarterly, 11, 182-201.

Hinds, L., and Murphy, T., 2007. Public satisfaction with police: Using procedural justice to improve police legitimacy. Australian and New Zealand journal of criminology, 40(1), $27-42$

Hohl, K., Bradford, B., and Stanko, E. A., 2010. Influencing trust and confidence in the London Metropolitan Police. British journal of criminology, 50, 491-513.

Hunter, A., 1985. Private, parochial and public social orders: The problem of crime and incivility in urban communities. The challenge of social control: Citizenship and institution building in modern society, 230-242. 
Innes, M., 2004. Signal crimes and signal disorders: notes on deviance as communicative action. The British journal of sociology, 55(3), 335-355.

Innes, M. and Fielding, N., 2002. From community to communicative policing: Signal crimes and the problem of public reassurance. Sociological research online, 7(2).

Innes, M., Lowe, T., Mackenzie, H., Murray, P., Roberts, C., and Twyman, L., 2004. The signal crimes perspective: Interim findings. Guildford, UK: University of Surrey.

Jackson, J., Bradford, B., Stanko, B., and Hohl, K., 2012. Just authority: Trust in the police in England and Wales. Willan Publishing.

Kochel, T. R., 2009. Legitimacy as a mechanism for police to promote collective efficacy and reduce crime and disorder. (Doctor of Philosophy), George Mason University.

Kochel, T. R., 2012. Can police legitimacy promote collective efficacy? Justice quarterly, 29(3), 384-419.

Kubrin, C. E., and Weitzer, R., 2003. New directions in social disorganization theory. Journal of research in crime and delinquency, 40(4), 374-402.

LaFree, G., 1998. Losing legitimacy: Street crime and the decline of social institutions in America. Boulder, CO: Westview Press.

Maimon, D., Browning, C. R., and Brooks-Gunn, J., 2010. Collective efficacy, family attachment, and urban adolescent suicide attempts. Journal of health and social behavior, 51(3), 307-324.

Mazerolle, L., Bennett, S., Antrobus, E., and Eggins, E., 2011. Key findings of the Queensland Community Engagement Trial CEPS Briefing Paper Series.

Mazerolle, L., Wickes, R. L., and McBroom, J., 2010. Community variations in violence: The role of social ties and collective efficacy in comparative context. Journal for research in crime and delinquency, 47(1), 3-30. 
Mazerolle, L., et al., 2012. Community variations in crime: a spatial and ecometric analysis wave 3: technical report no. 1 study methods and basic statistics. Brisbane: Australian Research Council.

Murphy, K., Hinds, L., and Fleming, J., 2008. Encouraging public cooperation and support for police. Policing and society, 18(2), 136-155.

Murphy, K., et al., 2012. The community capacity survey-face-to-face ethnic minority interviews: methodology and preliminary findings. ARC Centre for excellence in policing and security.

Pickett JT, Chiricos T, Golden KM and Gertz M (2012) Reconsidering the relationship between perceived neighborhood racial composition and whites' perceptions of victimization risk: Do racial stereotypes matter? Criminology 50(1): 145-186.

Rabe-Hesketh, S., and Skrondal, A., 2012. Multilevel and longitudinal modeling using STATA (Vol. 1: Continuous responses). College Station, TX: Stata Press.

Raudenbush, S. W, 1989. "Centering" predictors in multilevel analysis: Choices and consequences. Multilevel modelling newsletter, 1(2): 10-12.

Raudenbush, S. W., and Bryk, A. S., 2002. Heirarchical linear models: Applications and data analysis methods (2nd ed. Vol. 1). Thousand Oaks, C.A.: Sage.

Reisig, M. D., Bratton, J., and Gertz, M. G., 2007. The construct validity and refinement of process-based policing measures. Criminal justice and behavior, 34(8), 1005-1028.

Reisig, M. D., and Parks, R. B., 2000. Experience, quality of life and neighborhood context: A hierarchical analysis of satisfaction with police. Justice quarterly, 17(3), 607-630.

Renauer, B. C., 2007. Is neighborhood policing related to informal social control? Policing: An international journal of police strategies and management, 30(1), 61-81.

Rhineberger-Dunn, G. M., and Carlson, S. M., 2009. Confirmatory factor analyses of collective efficacy and police satisfaction. Journal of crime and justice, 32(1), 125-154. 
Sampson, R. J., 2013. The place of context: A theory and strategy for criminology's hard problems. Criminology, 51(1), 1-31.

Sampson, R. J., Raudenbush, S. W., and Earls, F., 199. Neighborhoods and violent crime: A multilevel study of collective efficacy. Science, 277, 918-924.

Silver, E., and Miller, L. L., 2004. Sources of informal social control in Chicago neighborhoods. Criminology, 42(3), 551-583.

Skogan, W. G., 2006. The promise of community policing. Police innovation: Contrasting perspectives, 27-43.

Sunshine, J., and Tyler, T. R., 2003. The role of procedural justice and legitimacy in shaping public support for policing. Law and society review, 37(3), 513-548.

Sun, I. Y., Triplett, R. A., and Gainey, R. R., 2004. Social organization, legitimacy of local institutions and neighbourhood crime: an exploratory study of perceptions of the police and local government. Journal of crime and justice, 27(1), 33-60.

Tankebe, J., 2009. Self-help, policing, and procedural justice: Ghanaian vigilantism and the rule of law. Law and society review, 43(2), 245-270.

Tankebe, J., 2013. Viewing things differently: The dimensions of public perceptions of police legitimacy. Criminology, 51(1), 103-135.

Triplett, R. A., Gainey, R. R., and Sun, I. Y., 2003. Institutional strength, social control and neighbourhood crime rates. Theoretical criminology, 7(4), 439-467.

Tyler, T. R.., 2006. Why people obey the law. Princeton, NJ: Princeton University Press.

Tyler, T. R., and Fagan, J., 2008. Legitimacy and cooperation: Why do people help the police fight crime in their communities? Ohio state journal of criminal law, 6, 231-276.

Tyler, T. R., and Huo, Y. J., 2002. Trust in the law. New York: Russell Sage.

Tyler, T. R., and Wakslak, C. J., 2004. Profiling and police legitimacy: Procedural justice, attributions of motive, and acceptance of police authority. Criminology, 42(2), 253-282. 
Warner, B. D., 2007. Directly intervene or call the authorities? A study of forms of neighborhood social control within a social disorganization framework. Criminology, 45(1), 99-129.

Warner, B. D., and Burchfield, K., 2010. Misperceived neighborhood values and informal social control. Justice quarterly, 28(4), 606-630.

Zhang, L., Messner, S. F., and Liu, J., 2007. A multilevel analysis of the risk of household burglary in the city of Tianjin China. British journal of criminology, 47, 918-937. 